\title{
ANALISIS TINGKAT KERUSAKAN JALAN LENTUR DENGAN METODE PAVEMENT CONDITION INDEX (PCI) STUDI KASUS RUAS JALAN POROS LAMASI-WALENRANG KABUPATEN LUWU
}

\author{
Muhammad Fikri' \\ ${ }^{1}$ Dosen FT Universitas Andi Djemma Palopo \\ 1'mufikri.ft03@gmail.com
}

\begin{abstract}
Abstrak
Faktor yang sering dianggap menjadi masalah terhadap kerusakan jalan bagi masyrakat yang ada disekitar jalan Poros Kecamatan Lamasi ialah faktor kendaraan yang sering melintas diruas jalan yang melebihi beban muatan (overload), di samping itu mungkin masih banyak faktor penyebab kerusakan lainnya. Adapun tujuan dari penelitian ini adalah mengidentifikasi kondisi perkerasan jalan untuk mengetahui jenis dan tingkat kerusakan yang terjadi serta menghitung jenis dan tingkat kerusakan jalan agar diperoleh nilai Pavement Condition Index (PCI) sehingga dapat menentukan jenis perbaikan dan pemeliharaan yang sesuai. Metode yang digunakan adalah dengan mengevaluasi jenis - jenis kerusakan yang terjadi sesuai dengan tingkat kerusakannya yaitu dengan cara mengukur panjang, luas dan kedalaman terhadap tiap - tiap jenis kerusakan serta menghitung nilai (density, deduct value, total deduct value, corrected deduct value), sehingga kemudian akan didapat nilai PCI yang merupakan acuan dalam penilaian kondisi perkerasan jalan. Berdasarkan hasil perhitungan maka didapat nilai Pavement Condition Index (PCI) untuk ruas jalan poros Kecamatan Lamasi, Kabupaten Luwu adalah 53,92. Dari nilai PCI yang didapat maka ruas jalan ini termasuk dalam klasifikasi sedang (fair).
\end{abstract}

Kata kunci : Jalan Lentur, Pavement Condition Index, Density, Deduct Value

\section{PENDAHULUAN}

Salah satu penyebab utama meningkatnya kerusakan jalan yang parah di wilayah jalan Poros Kecamatan Lamasi, Kabupaten Luwu ialah faktor kendaraan yang sering melintas diruas jalan yang melebihi beban muatan (overload). Menurunnya tingkat pelayanan jalan ditandai dengan adanya kerusakan pada lapisan struktur perkerasan jalan, kerusakan yang terjadi juga bervariasi pada setiap segmen di sepanjang ruas jalan dan apabila dibiarkan dalam jangka waktu yang cukup lama, maka akan dapat memperburuk kondisi lapisan perkerasan jalan sehingga dapat mempengaruhi keamanan, kenyamanan, dan kelancaran dalam berlalu lintas.

Oleh karena itu perlu diidentifikasi kondisi perkerasan jalan untuk mengetahui jenis dan tingkat kerusakan yang terjadi, serta perlu diketahui jenis dan tingkat kerusakan jalan untuk mendapatkan nilai Pavement Condition Index (PCI) sehingga dapat menentukan jenis perbaikan dan pemeliharaan yang sesuai.

Pavement Condition Index (PCI) adalah sistem penilaian kondisi perkerasan jalan berdasarkan jenis, tingkat dan luas kerusakan yang terjadi, dan dapat digunakan sebagai acuan dalam usaha perbaikan dan pemeliharaan. Pentingnya perencanaan sistem managemen adalah kemampuan dalam menentukan pekerjaan dan penilaian dari kondisi perkerasan yang ada dengan tujuan untuk mengidentifikasikan keadaan dari lapisan perkerasan jalan tersebut. Kondisi perkerasan sangat bervariasi, dalam satu ruas jalan bisa terdapat beberapa macam keadaan sesuai dengan jenis dan tingkat kerusakan. Oleh karena itu Pavement Condition Index (PCI) suatu jalan haruslah dapat ditentukan.

Jenis dan tingkat kerusakan perkerasan jalan menurut metode Pavement Condition Index (PCI) dibedakan menjadi: 


\section{1) Alligator Cracking (retak kulit buaya)}

Retak yang saling merangkai membentuk kotak-kotak kecil yang menyerupai kulit buaya. Kerusakan ini disebabkan karena konstruksiperkerasan yang tidak kuat dalam mendukung beban lalu lintas yang berulang ulang. Pada mulanya terjadi retakretak halus, akibat beban lalu lintas yang berulang menyebabkan retak-retak halus terhubung membentuk serangkaian kotak-kotak kecil yang memiliki sisi tajam sehingga menyerupai kulit buaya. Retak buaya biasa terjadi hanya di daerah yang dilalui beban lalu lintas yang berulang dan biasanya disertai alur, sehingga tidak akan terjadi di seluruh daerah kecuali seluruh area jalan dikenakan arus lalu lintas.

Cara mengukur kerusakan yang terjadi adalah dengan menghitung luasan retak. Tingkat kerusakan alligator cracking (retak kulit buaya) dibagi menjadi kerusakan ringan (low) yang ditandai dengan serangkaian retak halus yang saling terhubung tanpa ada retakan yang pecah, kerusakan sedang (medium) yang ditandai dengan serangkaian retak yang terhubung membentuk kotak-kotak kecil dan pola retak sudah cukup kelihatan jelas karena sudah terdapat retak yang mulai pecah, dan kerusakan berat (high) yang ditandai dengan serangkaian retak menyerupai kulit buaya yang keseluruhan retaknya sudah pecah sehingga jika dibiarkan dapat menyebabkan terjadinya alur bahkan lubang pada jalan.

2) Corrugation (Keriting)

Keriting adalah kerusakan lapisan perkerasan yang tampak seperti bergelombang dimana jarak antara tiap gelombang sangat dekat. Tingkat kerusakan diukur dari beda tinggi antar lembah dan puncak gelombang. Penyebab kerusakan dimungkinkan oleh terjadinya pergeseran bahan perkerasan, lapis perekat antara lapis permukaan dan lapis pondasi tidak memadai, pengaruh kendaraan yang sering berhenti dan berjalan secara tiba-tiba. Tingkat kerusakan keriting dapat diukur berdasarkan kedalaman keriting yang terjadi. Untuk tingkat kerusakan ringan (low) kedalaman $<1 / 2$ inchi, untuk (medium) kedalaman $1 / 2-1$ inchi, dan untuk tingkat kerusakan parah (high) kedalaman $>1$ inchi.

3) Patching and Utility Cut Patching (Tambalan)

Tambalan adalah wilayah perkerasan yang telah diganti menjadi baru untuk memperbaiki perkerasan yang ada. Tambalan dianggap merupakan cacat jalan walaupun sudah di kerjakan dengan sangat baik. Idetifikasi terhadap tambalan ini biasanya diukur dengan menghitung luasan tambalan. Tambalan dibagi berdasarkan tingkat kerusakannya yaitu tingkat kerusakan rendah (low), sedang (medium), dan berat (high), sesuai dengan bentuk tambalannya.

4) Potholes (Lubang)

Lubang biasanya berukuran tidak begitu besar (diameter $<90 \mathrm{~cm}$ ) berbentuk seperti mangkuk yang tidak beraturan dengan pinggiran tajam. pertumbuhan lubang semakin besar diakibatkan kondisi air yang tergenang pada badan jalan. Lubang pada dasarnya bermula dari retak- retak yang semakin parah akibat air meresap hingga ke lapisan jalansehingga menyebabkan sifat saling mengikat aggregat dalam lapisan menjadi berkurang.

Berdasarkan tingkat kerusakannya, lubang dapat di bagi menjadi kerusakan rendah (low), sedang (medium), dan buruk (high). Ketentuannya dapat di jelaskan pada table berikut :

Tabel 1. Tingkat kerusakan lubang 


\begin{tabular}{|c|c|c|c|}
\hline \multirow{2}{*}{ Kedalaman (Inchi) } & \multicolumn{3}{|c|}{ Diameter (Inchi) } \\
\cline { 2 - 4 } & $4-8$ & $>8-18$ & $>18-30$ \\
\hline $0,5-1$ & $\mathrm{~L}$ & $\mathrm{~L}$ & $\mathrm{M}$ \\
\hline$>1-2$ & $\mathrm{~L}$ & $\mathrm{M}$ & $\mathrm{H}$ \\
\hline$>2$ & $\mathrm{M}$ & $\mathrm{M}$ & $\mathrm{H}$ \\
\hline
\end{tabular}

\section{5) Rutting (Alur)}

Alur adalah penurunan setempat yang terjadi pada jalur roda kendaraan, alur pada permukaan jalan ada yang disertai retak dan tanpa disertai retak. Alur tidak terjadi di seluruh permukaan badan jalan, hanya pada daerah yang dilalui roda kendaraan. Dapat disebabkan adanya muatan yang berlebih sehingga menyebabkan deformasi yang permanen pada permukaan jalan. Jika alur sering tergenang air maka dapat meningkat menjadi lubang.

Berdasarkan tingkat kerusakannya, alur di bagi menjadi 3 yaitu, tingkat kerusakan rendah (low) dengan kedalaman peurunan 1/4-1/2 inchi, tingkat kerusakan sedang (medium) dengan kedalaman penurunan $>1 / 2-1$ inchi, dan tingkat kerusakan buruk (high) dengan kedalaman penurunan $>1$ inchi.

6) Shoving (Jembul)

Jembul umumya terjadi di sekitar alur roda kendaraan di tepi perkerasan dan sifatnya permanen. Kerusakan ini disebabkan oleh arus lalu lintas yang melebihi beban standar. Cara mengukur jembul adalah dengan mengukur luasan permukaan sesuai dengan tingkat kerusakan yang terjadi.

\section{METODOLOGI PENELITIAN}

Dalam melaksanakan penilaian kondisi perkerasan di lakukan dalam beberapa tahap pekerjaan. Tahap awal adalah dengan mengevaluasi jenis - jenis kerusakan yang terjadi sesuai dengan tingkat kerusakannya yaitu dengan cara mengukur panjang, luas dan kedalaman terhadap tiap- tiap jenis kerusakan. Kemudian pada tahap berikutnya perlu dihitung nilai (density, deduct value, total deduct value, corrected deduct value), sehingga kemudian akan didapat nilai PCI yang merupakan acuan dalam penilaian kondisi perkerasan jalan. Density atau kadar kerusakan adalah persentasi luasan dari suatu jenis kerusakan terhadap luasan suatu unit segmen yang diukur dalam meter persegi atau meter panjang. Nilai density suatu jenis kerusakan juga dibedakan berdasarkan tingkat kerusakan. Rumus mencari nilai Density :

Untuk jenis kerusakan Alligator Cracking, Corrugation, Patching and Utility Cut Patching, Rutting, Shoving adalah :

$$
\text { Density : } \frac{\mathrm{Ad}}{\mathrm{As}} \times 100 \%
$$

Sedangkan untuk jenis kerusakan potholes adalah :

$$
\text { Density : } \frac{\mathrm{N}}{\mathrm{As}} \times 100 \%
$$

dimana :

Ad $=$ Luas total jenis kerusakan untuk tiap tingkat kerusakan $\left(\mathrm{m}^{2}\right)$

As $=$ Luas total unit segmen $\left(\mathrm{m}^{2}\right)$

$\mathrm{N}=$ Jumlah banyak lubang

Deduct value adalah nilai pengurangan untuk tiap jenis kerusakan yang 
diperoleh dari kurva hubungan antara density dan deduct value. Deduct value juga dibedakan atas tingkat dan jenis kerusakan. (1) Alligator Cracking (retak kulit buaya), adapun kurva hubungan antara density dan deduct value untuk jenis kerusakan alligator cracking dapat dilihat pada gambar dibawah ini. Sesuai dengan tingkatan kerusakannya, L (low severity level), M (medium severity level), dan $\mathrm{H}$ (high severity level); (2) Corrugation (keriting), adapun kurva hubungan antara density dan deduct value untuk jenis kerusakan corrugation dapat dilihat pada gambar dibawah ini. Sesuai dengan tingkatan kerusakannya, L (low severity level), M (medium severity level), dan $\mathrm{H}$ (high severity level); (3) Patching and Utility Cut Patching (tambalan), adapun kurva hubungan antara density dan deduct value untuk jenis kerusakan patching and utility cut patching dapat dilihat pada gambar dibawah ini. Sesuai dengan tingkatan kerusakannya, L (low severity level), M (medium severity level), dan $\mathrm{H}$ (high severity level); (4) Potholes (lubang), adapun kurva hubungan antara density dan deduct value untuk jenis kerusakan potholes dapat dilihat pada gambar dibawah ini. Sesuai dengan tingkatan kerusakannya, L (low severity level), M (medium severity level), dan H (high severity level); (5) Rutting (alur), adapun kurva hubungan antara density dan deduct value untuk jenis kerusakan rutting dapat dilihat pada gambar dibawah ini. Sesuai dengan tingkatan kerusakannya, L (low severity level), M (medium severity level), dan $\mathrm{H}$ (high severity level); (6) Shoving (Jembul), adapun kurva hubungan antara density dan deduct value untukjenis kerusakan shoving dapat dilihat pada gambar dibawahini. Sesuai dengan tingkatan kerusakannya, L (low severity level), M (medium severity level), dan $\mathrm{H}$ (high severity level).

Setelah didapat nilai deduct value dari tiap - tiap jenis kerusakan dan tingkat kerusakannya, maka akan didapatkan nilai total deduct value untuk tiap jenis kerusakan dan tingkat kerusakan pada suatu unit penelitian. Total deduct value ini didapatkan dengan menjumlahkan seluruh nilai dari deduct value tiap kerusakan jalan pada tiap segmen. Selanjutnya, Corrected Deduct Value (CDV) diperoleh dari kurva hubungan antara nilai TDV dengan nilai CDV dengan pemilihan lengkung kurva sesuai dengan jumlah nilai individual deduct value yang mempunyai nilai lebih besar dari 5. Jika nilai Corrected Deduct Value (CDV) diketahui, maka nilai Pavement Condition Index (PCI) untuk tiap unit dapat diketahui dengan rumus :

$$
P C I(s)=100-C D V
$$

dimana :

$\mathrm{PCI}(\mathrm{s})=$ Pavement Condition Index tiap unit/segmen

$\mathrm{CDV}=$ Corrected Deduct Value untuk tiap unit/segmen

Untuk nilai PCI secara keseluruhan :

Rumus :

dimana :

$$
P C I=\frac{\sum P C I(s)}{N}
$$

PCI = Nilai PCI total

PCI(s) = Nilai PCI untuk tiap unit/segmen

$\mathrm{N}=$ Jumlah unit/segmen

Dari nilai Pavement Condition Index (PCI) masing - masing unit penelitian dapat diketahui kualitas lapis perkerasan untuk unit segmen berdasarkan kondisi tertentu yaitu sempurna (excellent), sangat baik (very good), baik (good), sedang (fair), jelek (poor), sangat jelek (very poor), dan gagal (failed). Adapun pembagian nilai kualitas kondisi perkerasan adalah sebagai berikut : 
Tabel 2. Klasifikasi kondisi perkerasan

\begin{tabular}{|c|c|}
\hline Tingkat Kondisi Perkerasan & Rentang Nilai \\
\hline Sempurna (Excellent) & $85-100$ \\
\hline Sangat Baik (Very Good) & $70-85$ \\
\hline Baik (Good) & $55-70$ \\
\hline Sedang (Fair) & $40-55$ \\
\hline Jelek (Poor) & $25-40$ \\
\hline Sangat Jelek (Very Poor) & $10-25$ \\
\hline Gagal (Failed) & $0-10$ \\
\hline
\end{tabular}

Dari hasil klasifikasi kualitas perkerasan jalan, maka dapat ditentukan urutan jenis pemeliharaan yang sesuai untuk di lakukan. Jika nilai PCI $<50$ (untuk jalan primer), dan nilai PCI < 40 (untuk jalan sekunder), maka diusulkan jenis pemeliharaan mayor yaitu pemeliharaan terhadap keseluruhan unit jalan melalui overlay atau rekonstruksi terhadap jalan tersebut. Sedangkan jika nilai PCI > 50 (untuk jalan primer), dan nilai PCI > 40 (untuk jalan sekunder) maka dapat dilakukan program pemeliharaan rutin sebagai usulan penanganannya.

\section{HASIL DAN PEMBAHASAN}

Berdasarkan data kerusakan yang didapat dari survey di lapangan maka selanjutnya akan dilakukan penilaian kondisi perkerasan jalan untuk menentukan nilai PCI pada ruas jalan poros lamasi. Dalam melakukan kondisi perkerasan jalan maka ruas yang ditinjau dibagi menjadi segmen-segmen, yang masing-masing panjang segmennya adalah 100 meter.

Berdasarkan data kerusakan yang telah diperoleh, maka selanjutnya akan dicari nilai density (kadar kerusakan) tiap jenis kerusakan ini. Selanjutnya, dari nilai density ini akan didapat nilai angka pengurangan (deduct value), total nilai angka pengurangan atau nilai Total Deduct Value (TDV), nilai Corrected Deduct Value (CDV), dan kemudian akan didapat nilai PCI.

a) Retak kulit buaya (Alligator Cracking)

Luas Kerusakan

Luas Area

Tingkat Kerusakan (Severity level)

Kadar Kerusakan (Density)

Nilai Pengurangan (Deduct Value)

b) Tambalan (Patching)

Luas Kerusakan

Luas Area

Tingkat Kerusakan (Severity level)

Kadar Kerusakan (Density)

Nilai Pengurangan (Deduct Value)

Nilai Pengurangan (deduct value) didapat dari grafik hubungan density dan deduct value dibawah ini : 


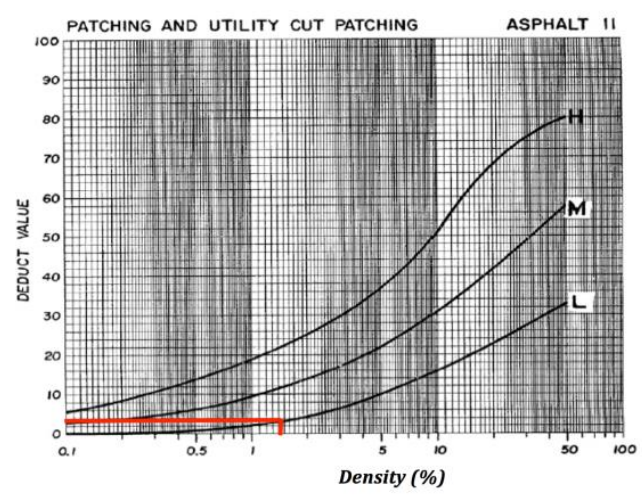

Gambar 1. Grafik hubungan density dan deduct value patching

c) Lubang (Potholes)

Luas Kerusakan

Luas Area

Tingkat Kerusakan (Severity level)

Kadar Kerusakan (Density)

Nilai Pengurangan (Deduct Value)

$$
\begin{aligned}
& =12,07 \mathrm{~m}^{2} \\
& =4,5 \times 100=450 \\
& =\operatorname{Medium}(\mathrm{M}) \\
& =4,682 \% \\
& =50
\end{aligned}
$$

Nilai Pengurangan (deduct value) didapat dari grafik hubungan density dan deduct value dibawah ini :

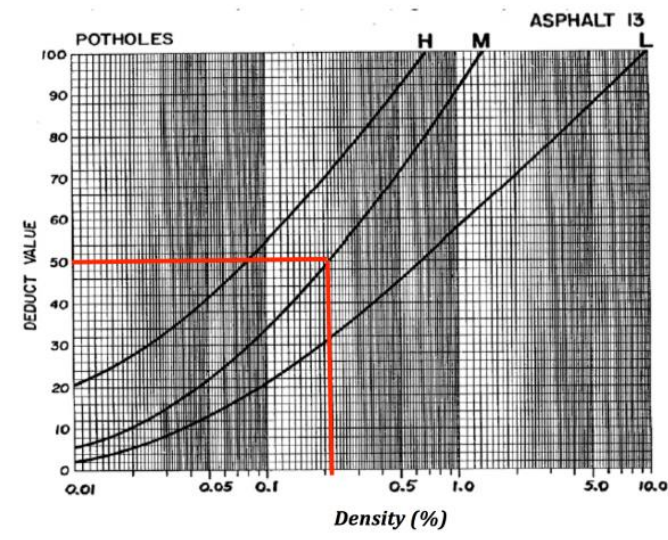

Gambar 2. Grafik hubungan density dan deduct value potholes

d) Jembul (Shoving)

Luas Kerusakan

$$
\begin{aligned}
& =18,24 \mathrm{~m}^{2} \\
& =4.5 \times 100=450 \\
& =\text { Medium }(\mathrm{M}) \\
& =4,053 \% \\
& =12
\end{aligned}
$$

Luas Area

Kadar Kerusakan (Density)

Nilai Pengurangan (Deduct Value)

Nilai Pengurangan (deduct value) didapat dari grafik hubungan density dan deduct value dibawah ini : 


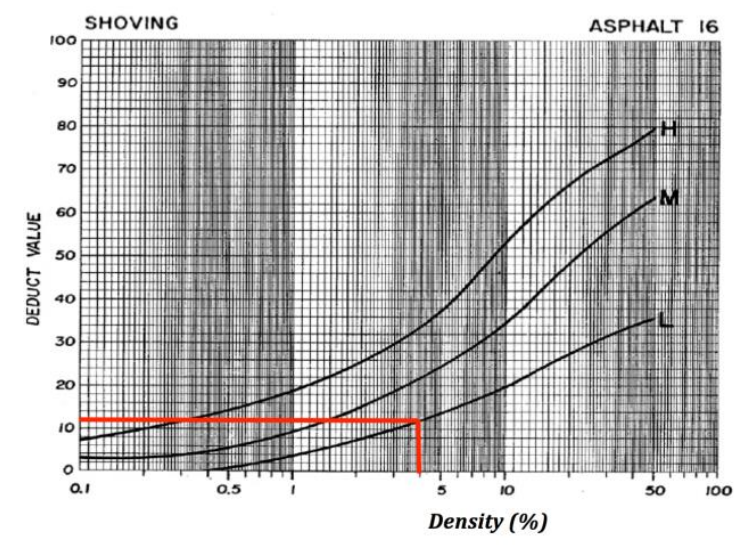

Gambar 3. Grafik hubungan density dan deduct value Shoving

Total Deduct Value $($ TDV $)=44+3+50+12=109$

Corrected Deduct Value $(\mathrm{CDV})=62$

Nilai Corrected Deduct Value (CDV) didapat dari grafik hubungan antara Total Deduct Value (TDV) dan Corrected Deduct Value (CDV) di bawah ini :

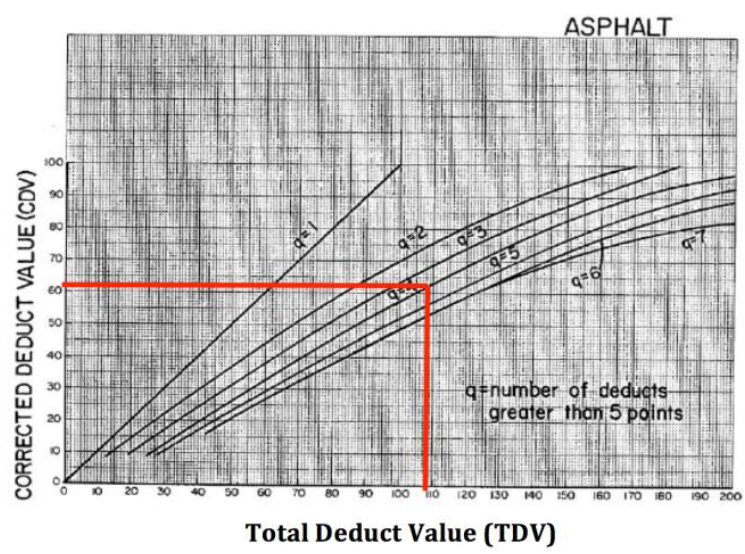

Gambar 4. Grafik hubungan total $T D V$ dan $C D V$

Sehingga Nilai PCI Untuk Segmen 1 adalah :

$\mathrm{PCI}=100-\mathrm{CDV}$

$\mathrm{PCI}=100-62=38$

Analisis tersebut dilakukan pada tiap segmen, sehingga diperoleh nilai PCI pada tiap segmen. Dari 50 segmen diperoleh total nilai Pavement Condition Index (PCI) adalah 2696. Sehingga nilai rata - rata Pavement Condition Index (PCI) untuk ruas jalan Poros Kecamatan Lamasi, Kabupaten Luwu adalah sebagai berikut :

$$
\begin{array}{r}
\text { PCI Rata }- \text { rata }=\frac{\text { Total Nilai PCI }}{\text { Jumlah Segmen Jalan }} \\
\text { PCI Rata }- \text { rata }=\frac{2696}{50} \\
\text { PCI Rata }- \text { rata }=53,92
\end{array}
$$

Berdasarkan hasil perhitungan maka didapat nilai Pavement Condition Index (PCI) untuk ruas jalan poros Kecamatan Lamasi, Kabupaten Luwu adalah 53,92. Dari nilai PCI yang didapat maka ruas jalan ini termasuk dalam klasifikasi 
sedang (fair).

Tabel 4. Klasifikasi kondisi perkerasan

\begin{tabular}{|c|c|}
\hline Tingkat Kondisi Perkerasan & Rentang Nilai \\
\hline Sempurna (Excellent) & $85-100$ \\
\hline Sangat Baik (Very Good) & $70-85$ \\
\hline Baik (Good) & $55-70$ \\
\hline Sedang (Fair) & $40-55$ \\
\hline Jelek (Poor) & $25-40$ \\
\hline Sangat Jelek (Very Poor) & $10-25$ \\
\hline Gagal (Failed) & $0-10$ \\
\hline
\end{tabular}

Dari hasil klasifikasi kondisi perkerasan, maka dapat ditentukan jenis pemeliharaan yang sesuai untuk di lakukan pada ruas jalan Poros Kecamatan Lamasi, Kabupaten Luwu ialah program pemeliharaan rutin sebagai usulan penanganannya.

\section{PENUTUP}

Berdasarkan dari hasil pembahasan yang telah diuraikan, maka dapat diambil kesimpulan sebagai berikut: (1) dari hasil pengolahan data kita dapatkan nilai Pavement Condition Index (PCI) untuk ruas jalan Poros Kecamatan Lamasi, Kabupaten Luwu adalah 53,92. Dari nilai Pavement Condition Index (PCI) yang didapat maka ruas jalan termasuk dalam kualifikasi sedang (fair) dan berdasarkan hasil klasifikasi kondisi perkerasan maka ruas jalan ini termasuk dalam program pemeliharaan rutin sebagai usulan penanganannya; (2) dari semua jenis kerusakan yang terjadi kita ketahui kerusakan yang terbesar ialah kerusakan retak kulit buaya (Alligator Cracking) dengan luas $826,27 \mathrm{~m}^{2}$ sebanyak 33\%, kemungkinan penyebab kerusakan ini diakibatkan oleh beban lalu lintas yang berulang - ulang. Hal ini terjadi dikarenakan kendaraan (truk-truk) yang membawa hasil material yang melintasi ruas jalan sering mengalami kelebihan beban (overload).

\section{DAFTAR PUSTAKA}

Departement Of Defense, (2001), Paver Asphalt Surfaced Airfields Pavement Condition Index (PCI), UFC 3-270-06, Unified Facilities Criteria (UFC), USA.

Departement Of Defense, (2004), Pavement Maintenance Management, UFC 3-27008, Unified Facilities Criteria (UFC), USA.

Manurung, M.A., (2010), Evaluasi Tingkat Kerusakan Jalan Sebagai Dasar Penentuan Perbaikan Jalan, Departemen Teknik Sipil USU: Medan.

Suwandi, A., Sartono, W., Christady, H., (2008), Evaluasi Tingkat Kerusakan Perkerasan Jalan Dengan Metode Pavement Condition Index (PCI) Untuk Menunjang Pengambilan Keputusan, Forum Teknik Sipil No. XVIII, Yogyakarta, Indonesia.

Tri Utomo, S.H., (2001), Kajian Kondisi Perkerasan Jalan Arteri di Kabupaten Sleman Menggunakan Cara Pavement Condition Index, Universitas Gajah Mada : Yogyakarta. 